\title{
Research on Transformation and Development of Fabric Recycling
}

\section{Curriculum}

\author{
Ping $\mathrm{Hu}^{1}$ \\ ${ }^{1}$ Jiangxi Institute of Fashion Technology, Nanchang, Jiangxi, 330201
}

\section{KEYWORDS: Fabric Recycling; Curriculum Transformation and Development}

\begin{abstract}
Fabric recycling allows the fabric to get the original appearance of the shape change to promote their better improvement occurred in the texture, form and texture, so the original fabric single and flat appearance form to be changed, so that the fabric to reveal a new look, features and style, and let the fabric gradually formed rhythm, a sense of relief and a new form of three-dimensional garment material, so that the aesthetic effect of clothing is increased, so that the use of range and performance space has been expanded garment material, also can let artistic expression of garment strengthened. This article carried on the current development status fabric recycling analysis, and on this basis to explore the transformation of instructional design fabric recycling programs in education, and hope to enhance the educational effect of fabric recycling program to provide some help.
\end{abstract}

\section{Introduction}

Fabric recycling program has a strong practical. Through the study of fabric recycling program, students in the aesthetic principles based on the premise, based on the characteristics of the original fabric and form gradually changed, while the fabric of the original two-dimensional space tether broke, will be between two-dimensional and three-dimensional space into which the concept, resulting in the appearance of the fabric shape, the new visual effects to show up. Fabric recycling program is only in Fashion Design professional college courses occurs in the early 2000s, resulting in this course because the fabric is a major factor in the development of market demand and design market. When forming fabric recycling program, it has been well received by many students of all ages, and the main reason for this phenomenon is that it is able to provide students with professional clothing more innovative channels, so that the driving force behind the innovative design is increased.

\section{The Development Status of the Fabric Recycling}

China, as a textile big country, its industry in China also has a very big advantage, but it has been a lot of fabric production are lack of individuality and innovation, so as to make it the current pursuit of individuality and diversity of consumer demand difficult to meet, and to a large extent resulted in the design and production of fabrics is always in the low position [1]. Many high-end leather goods, or even well-known brands of imported fabric to make products in the expected appearance of the product design effects can be achieved. It means in this social situation, if the fabric of attention from creative design, the use of rich visual texture of fabric in the development process of the fabric, and then just be able to present our industrial fabric defects effectively fill complete and, thus, be able to present seek creative mainstream market demand for design trends and meet the 
ever-changing to be effective, but also allows fabric recycling is becoming an important moment in the development of the market deep-processing industry.

For now, whether domestic or foreign, or have had a lot of leather clothing designer fabric recycling as design elements, design techniques through a rich, let the fabric after the transformation can be more artistic, fun and personalized. For example: Japanese costume designer Miyake, has been become one hundred materials magician, he is best at is fabric recycling, in many of his works are applied to the fold, and thus allow the design out of the garment works more artistic color, fold has become one of the main elements of their work on behalf of the brand. Another example, in the Paris Fashion Week in 2007, the famous designer John Galliano the design work was highly infectious, in his design work on embroidery, fold, weaving and dyeing fabrics, such as recycling practices a lot Application, prompting the fabric look more features, refined styling and gorgeous clothing also make people feel contains a rich artistic appeal. In addition, in our country, there are many successful designers such as Ling Yali and Zhang Zhao-da, etc., they are recycled fabric representatives are keen to play again and creating fabrics, through a variety of techniques, such as sewing repeatedly split, folding twist wrapped, folding, dyeing and spinning and other methods, so that it gradually form a new shape.

In order to present clothing and leather goods market consumer demand been effectively met, the moment of a lot of clothing and leather goods design professional colleges and universities, and are beginning to fabric recycling programs more and more attention to it, even the originally clothing material and leather materials science courses in teaching content directly set up a separate out, the founder of a special fabric design and fabric creative recycling secondary courses. From a series of domestic and international design contest works it will be apparent that many winners or outstanding works are the fabrics on the market to buy back for recycling and created out, prompting a lot of work has unified and unique themed fabric appearance [2]. For example: In China International Young Fashion Designers Contest nineteenth game, "Zen Buddhism" work to get a gold medal, and this series of works is the use of fabric recycling practices, by quilting, embroidery fold and stick method, let gray fabrics become more dynamic vitality and spirit, but also to the beauty of artistic sculpture and turn state filled in the clothing appearance.

\section{The Teaching Design of Fabric Recycling Program Transition}

At this stage, teachers can allow students to consult some relevant information, collect some data or information to fully understand and master new teaching content. Teachers can first clothing fabric recycling process. Textile products and other ornaments of real objects or pictures to show to the students to observe, all kinds of fabric recycling process technique described in detail so as to enable students to fully mobilize the interest, on the basis of the concept of the fabric recycling tells students [3]. Second, teachers can show physical samples fabric recycling to observe the students, allow students fabric recycling species, forms and methods of understanding to be effective. It can make the process of teaching students in the classroom improvisation exercises, using the most direct method of disruption of the fabric treated by allowing students hands-on practice to encourage students to stimulate interest. Finally, teachers can allow students to market research methods and content when homework area to understand, and provides the students after the completion of the research, based on our current mainstream apparel market trends and product characteristics of the fabric recycling meaning and effect were discussed.

Fabric recycling has a variety of methods and materials during the process of teaching, first, the student teacher should be more common design guidelines summarize methods, such as: fabric recycling in embroidery, hand-painted, overlapping folds, weaving and dyeing and hollow, etc. 
practices, and systematic classification of these methods allow students to fabric recycling the basic principles can be effective control and memory [4]. However, teachers need to be noted that the fabric recycling is not just to teach the theory of knowledge, but should students' practical ability training, to help students more abstract concept gradually transformed into objects, and guide students in the clothing and leather product design introduced after the creation of the fabric, so that the students' actual level of implementation be effectively improved. In addition, in order to allow students to better innovation activities, so that the practical ability to be strengthened, it is necessary for students' creative and practical ability were cultured. Teachers can opening activities related to community activities to enable students to continue fabric recycling, which is the students' knowledge and application of integrated design capability cultivation practices carried out. In the activities, the students with similar interests can form a group with each other to discuss, with the strength of the team during the design, so that it can be designed to make the work more outstanding. But also allows students to get the sense of team training, allow students to fabric recycling product development process of all master and memory.

Specific methods students in basic courses on exercises to guide students to undermine the most basic techniques for processing of fabrics sorted out, such as: tearing, shearing, spinning, hollow, punching, burning and hot hole and so on. These techniques can be fabric surface flatness quickly destroyed, prompting its decorative effect gradually has a certain particularity. And other students have mastered the complete destruction of processing method based on the teacher can allow students freedom groups, a group of two, so that they approach other fabric recycling designs for joint analysis and research between each other, so that students can during the exploration, the more craft techniques and effects analysis, and gradually come up [5]. A trial basis is the core idea of the process.

\section{Conclusion}

In short, with the continuous development of society, the individual needs of the consumer market of leather clothing more improvement, innovative design fabric also become increasingly important to them, as a designer, you must be from a different perspective and breadth through new thinking Operation method, bold interpretation of the full amount of the product. And you want to do this step, you need to position in fashion design course was to enhance the fabric recycling programs, and the use of rational, scientific teaching methods to enable students to the basic fabric recycling techniques, principles and performance methods, etc. control, but also on the ability of students to use recycled fabrics in fashion design and cultured, encourage students to learn the theory of knowledge can be translated into practice, it will have a higher theoretical knowledge and practical ability of integrated applications talents out.

\section{References}

[1] Miao Xia. Fabric Recycling in Fashion Design Application Study [J]. Shandong Textile Economy, 2013,06: 77-78.

[2] Zhao Kaiqing. Fabric Re-Design Practice in Undergraduate Courses Taught in Professional Clothing Discussion [J]. Modern Decor (Theory), 2013,05: 244-245.

[3] Zou Yuan. Extension of Beauty-Reproduction Art Painting Clothing Material Recycling Program Extends Exploration [J]. Nanjing Art Institute (Fine Arts \& Design), 2013,04: 137-140.

[4] Zhang Xiumei. Applications and Innovative Value "Modular" Teaching in College "Fabric 
Recycling" Course [J]. Education and Vocation, 2013,27: 107-108.

[5] Gan Weiwei. Discussion about Fashion Design Professional "Clothing Materials" Teaching [J]. Packaging World, 2013,06: 63-65. 